\title{
Determinação sérica de haptoglobina, ceruloplasmina e $\alpha$ - glicoproteína ácida em cães com gastrenterite hemorrágica
}

\author{
Determination of serum haptoglobin, ceruloplasmin and acid \\ $\alpha$-glycoprotein in dogs with haemorrhagic gastroenteritis
}

\author{
Márcia Mery Kogika ${ }^{1}$ Daionety Aparecida Pereira ${ }^{2}$ Fernanda Elias $^{2}$ \\ Márcia Kikuyo Notomi ${ }^{2}$ Ericka Homann Delayte ${ }^{2}$ Reimy Kawahara ${ }^{2}$ \\ Mitika Kuribaiashi Hagiwara ${ }^{3}$
}

\section{RESUMO}

As proteinas de fase aguda (PFA) são proteinas plasmáticas, cujo estímulo à síntese ocorre de forma rápida e marcante em resposta à injúria tecidual. Estas proteínas permitem o diagnóstico de processos inflamatórios em animais com supressão ou depressão medular. Além disso, são úteis na monitorização da resolução tecidual de traumas ou inflamação e também na avaliação da resposta orgânica ao tratamento. Uma vez que a leucopenia é observada nos estádios iniciais da parvovirose canina, a dosagem das PFA pode permitir a avaliação do processo inflamatório sob estas condições. Considerando-se estas hipóteses, foram determinados os niveis séricos das PFA (haptoglobina, ceruloplasmina e $\alpha$-glicoproteina ácida) em 11 cães saudáveis e 11 cães leucopênicos com gastrenterite hemorrágica, com suspeita clínica de parvovirose canina. A avaliação estatística mostrou diferença significativa, com intervalo de confiabilidade de 99\% $(P<0,01)$ para a haptoglobina $(p<0,0064)$ e para a glicoproteina ácida $(p<$ $0,0042)$ e 95\% de confiança $(P<0,05)$ para a ceruloplasmina $(p<0,0478)$ quando comparada com o grupo controle. Em conclusão, cães com gastrenterite hemorrágica durante a fase leucopênica apresentaram niveis elevados de haptoglobina, ceruloplasmina e $\alpha$-glicoproteína ácida.

Palavras-chave: proteina de fase aguda, parvovírus canino, cães, haptoglobina,ceruloplasmina, $\alpha$ glicoproteína ácida.

\begin{abstract}
Acute phase proteins (APP) are serum proteins whose stimulus for the synthesis happens in a quick and intense manner in response to tissue injury. Those proteins allow the diagnosis of inflammatory process in animals with bone marrow depression and, also, they are useful in the follow up of tissue resolution of traumas or inflammation, as well as in the evaluation of the organic response of the treatment. As leukopenia is observed in the initial stage of the canine parvovirus infection, the dosage of APP can allow the evaluation of the inflammatory process under these conditions. According to these hypothesis, serum APP levels (haptoglobin, ceruloplasm and $\alpha$-acid-glycoprotein) in 11 healthy dogs and 11 leukopenic dogs with haemorrhagic gastroenteritis, clinically suspected of canine parvovirus infection, were measured. There was a significant difference, with confidence interval of $99 \%(P<0.01)$ for the haptoglobin $(p<0.0064)$ and the acid $\alpha$-glycoprotein $(p<0.0042)$ and $95 \%(P<0.05)$ of confidence for the ceruloplasmin $(p<0.0478)$ when compared to the control group. In conclusion, dogs with haemorrhagic gastroenteritis during the leukopenic phase showed high serum levels of haptoglobin, ceruloplasmin and $\alpha$-acid-glycoprotein.
\end{abstract}

Key words: acute phase protein, canine parvovirus, dogs, haptoglobin, ceruplasmin, $\alpha$-acid-glycoprotein.

\footnotetext{
${ }^{1}$ Médico Veterinário, Professor Doutor, Departamento de Clínica Médica, Faculdade de Medicina Veterinária e Zootecnia, Universidade de São Paulo (USP). Rua Orlando Marques Paiva, 87, 05588-000, Cidade Universitária, SP. E-mail: mmkogika@usp.br. Autor para correspndência.

${ }^{2}$ Médico Veterinário, Aluno do Curso de Pós-graduação, Departamento de Clínica Médica, Faculdade de Medicina Veterinária e Zootecnia, USP

${ }^{3}$ Médico Veterinário, Professor Titular, Departamento de Clínica Médica, Faculdade de Medicina Veterinária e Zootecnia, USP.
} 


\section{INTRODUÇ̃̃OO}

Como conseqüência a uma injúria, trauma ou infecção de um tecido, desenvolve-se no hospedeiro uma série complexa de reações que tem como finalidade inibir a continuidade do dano tecidual, isolando e destruindo o organismo agressor e ativando o processo de reparação necessária para o retorno do organismo às funções normais (BAUMANN \& GAULDIE, 1994). Há liberação de amplo espectro de mediadores por parte dos macrófagos teciduais e monócitos sangüíneos, dos quais as citocinas, principalmente o fator de necrose tumoral (FNT) e as interleucinas IL-1 e IL-6, são as principais mediadoras da síntese das proteínas de fase aguda séricas (GRUYS et al., 1994).A maioria dessas proteínas é formada por glicoproteínas sintetizadas pelos hepatócitos, como resposta à injúria tecidual, e são encontradas na circulação sangüínea (JAIN, 1989).

Na dependência da espécie animal, as PFA são consideradas indicadores mais fiéis da resposta sistêmica frente aos processos inflamatórios e infecciosos, quando comparadas a outras variáveis, tais como febre, aumento da taxa de hemossedimentação e/ou presença de leucocitose associados à neutrofilia (JAIN,1989). De modo geral, o estímulo à síntese de proteína de fase aguda ocorre no período de 6 a 8 horas após a injúria, sendo que a concentração máxima é alcançada em 2 a 5 dias. Porém, o pico e a persistência das concentrações plasmáticas destas proteínas dependem do metabolismo, extravasamento vascular e deposição tecidual (JAIN,1993).

Sugere-se que as determinações de haptoglobina e ceruloplasmina oxidase possam auxiliar na avaliação da inflamação em cães. Estas proteínas são consideradas seis vezes mais sensíveis na detecção da inflamação do que a determinação de fibrinogênio, a contagem de leucócitos totais e a contagem de neutrófilos segmentados e bastonetes (SOLTER 1991). A haptoglobina é uma alfa-2-proteína responsável pelo transporte de hemoglobina nas células do sistema mononuclear fagocitário para que haja a recuperação do íon ferro durante o processo de hemocaterese e na defesa contra microorganismos. Outros efeitos propostos incluem a modulação da função de linfócitos e macrófagos e a inibição da atividade da catepsina (HARVEY \& WEST, 1987). A concentração da haptoglobina aumenta em processos inflamatórios agudos, estresse e, às vezes, durante processos neoplásicos recentes (CORAZZA, 1997). Esta proteína foi mensurada em várias espécies animais, inclusive no cão, apresentando uma média de $104 \mathrm{mg} \mathrm{dl}^{-1}$, segundo HARVEY \& WEST (1987), sendo que SOLTER et al. (1991) obtiveram o valor de $56,0 \mathrm{mg} \mathrm{dl}^{-1}$.

A ceruloplasmina está presente no soro também sob a forma de alfa-1-globulina (SCHOSINSKY et al. 1974). A concentração de ceruloplasmina alterase significantemente após a indução de processo inflamatório em cães, ao contrário do que se observa em humanos (CONNER et al., 1988). Os níveis plasmáticos desta proteína aumentam nos processos inflamatórios, infecciosos, virais e parasitários, enquanto o decréscimo é observado ao nascimento, desnutrição, deficiência na absorção de nutrientes, nefrose e moléstias hepáticas associadas à intoxicação de cobre (JAIN, 1993). Esse mesmo autor, em trabalho publicado em 1989, refere valores normais para a ceruloplasmina entre $15-60 \mathrm{mg} \mathrm{dl}^{-1}$.

A PFA $\alpha$-glicoproteína ácida (mucoproteína ou seromucóide) é uma proteína que participa fundamentalmente ligando-se à maioria das drogas básicas, tais como agentes bloqueadores e antiarrítmicos (DELLO et al., 1988). A concentração sérica desta proteína altera-se significativamente após um processo inflamatório (CONNER et al., 1988). Em estudos realizados por GANROT (1973), nos quais avaliou-se a $\alpha$-glicoproteína ácida em cães normais, observaram-se níveis séricos de 0,5 a $0,6 \mathrm{~g} \mathrm{~L}^{-1} \mathrm{e}$, ao se induzir o processo inflamatório, esta PFA apresentou rápido e significativo aumento, com vida média de aproximadamente 5,5 dias. À semelhança de GANROT (1973), DELLO et al. (1988) verificaram valores de 0,47 $\pm 0,09 \mathrm{~g} \mathrm{~L}^{-1}$ em cães normais e $2,85 \pm 0,51 \mathrm{~g} \mathrm{~L}^{-1}$ em animais com doença inflamatória.

A gastrenterite hemorrágica (GEH) em cães, causada pelo parvovirus canino (CPV) ocorre principalmente em cães jovens, não vacinados e tem como característica alta morbidade e mortalidade (BAGGINI, 1991).A infecção pelo CPV ocorre através da via fecal-oral (SHERDING, 1998) com período de incubação de 3 a 14 dias, após o qual os pacientes podem apresentar apatia e hipertermia momentânea de até $41^{\circ} \mathrm{C}$, vômitos incoercíveis, GEH, acentuada desidratação e caquexia (BAGGINI, 1991). Por possuir afinidade pelas células de rápida divisão do intestino, da medula óssea e dos tecidos linfóides, o CPV causa necrose da cripta intestinal, diarréia intensa, leucopenia e esgotamento linfóide (SHERDING, 1988). Em 60\% dos casos de parvovirose canina aguda, foi observada leucopenia, com desvio à esquerda no exame hematológico inicial e em $100 \%$ dos casos, entre o segundo e terceirodia de evolução da doença (HAGIWARA et al. 1984), com normalização ou tendência à leucocitose entre o quinto e oitavo dia, indicando-se, assim, o caráter agudo do processo inflamatório decorrente da infecção. 
Considerando-se que nem sempre os cães acometidos pela doença são submetidos ao exame clínico no momento em que apresentam leucopenia e em face às vantagens apresentadas pelas PFA como indicadoras do processo inflamatório agudo que permite o monitoramento da resolução tecidual e da resposta ao tratamento instituído, o objetivo deste trabalho foi avaliar os níveis séricos de haptoglobina, ceruloplasmina e $\alpha$ glicoproteína ácida em cães com GEH.

\section{MATERIAL EMÉTODOS}

Foram avaliados 22 cães jovens, com idade inferior a 6 meses. O Grupo I foi constituído por 11 animais saudáveis e o Grupo II por 11 animais que foram atendidos no Hospital Veterinário (Serviço de Pronto Atendimento Médico de Pequenos Animais do Departamento de Clínica Médica) com sinais clínicos de GEH aguda e leucopenia acentuada $(2.925 \pm 623,04$ leucócitos $\mathrm{mm}^{-3}$ ), o que permitiu estabelecer o diagnóstico presuntivo de parvovirose canina. De todos os animais foram colhidas amostras de sangue por venopunção jugular, utilizando-se tubos Vacutainer® com EDTA e tubos sem anticoagulante (Tubos SST ${ }^{\circledR}$ ) para a realização do hemograma e para a determinação das PFA, respectivamente. As amostras de sangue para a realização do hemograma foram processadas em menos de 24 horas e o soro obtido foi armazenado a $-20^{\circ} \mathrm{C}$, no período máximo de seis meses.

Para a determinação de ceruloplasmina, foi utilizado o método de SCHOSINSKY et al. (1974) e a leitura da reação foi realizada em espectrofotômetro (E$225 \mathrm{D}-\mathrm{CELM}^{\circledR}$ ) com absorbância $(\lambda)$ de $540 \mathrm{~nm}$. A haptoglobina e a $\alpha$-glicoproteína ácida foram determinadas de acordo com a metodologia descrita por ELSON (1974) e DE LA HUERGA et al. (1956), com $\lambda=380$ e $400 \mathrm{~nm}$ para haptoglobina e $\lambda=400 \mathrm{~nm}$ para $\alpha$ glicoproteína ácida. Para a análise dos dados obtidos, foram calculados, a média e o erro padrão da média dos parâmetros avaliados nos Grupos I e II, aplicando-se o teste $t$-student, sendo $\alpha=0,05$.

\section{RESULTADOS}

Os valores individuais, máximo e mínimo, obtidos das proteínas de fase aguda, haptoglobina, ceruloplasmina e $\alpha$-glicoproteína ácida, de cães saudáveis e com GEH estão apresentados nas tabelas 1 e 2 , respectivamente. Na tabela 3 e figura 1, encontram-se os valores médios e o desvio padrão da média das PFA analisadas, observando-se que os valores de haptoglobina, ceruloplasmina e $\alpha$-glicoproteína ácida são diferentes entre os animais do grupo I e II, sendo $p<0,01$ para os dois primeiros parâmetros e $\mathrm{p}<0,05$ para o último.
Tabela 1 - Valores individuais, máximos e mínimos da haptoglobina, ceruloplasmina e $\alpha$-glicoproteína ácida séricas em cães saudáveis com idade inferior a 6 meses . São Paulo, 2000.

\begin{tabular}{lccc}
\hline Animal & $\begin{array}{c}\text { Haptoglobina } \\
\left(\mathrm{g} \mathrm{L}^{-1}\right)\end{array}$ & $\begin{array}{c}\text { Ceruloplasmina } \\
\left(\mathrm{U} \mathrm{l}^{-1}\right)\end{array}$ & $\begin{array}{c}\alpha \text {-Glicoproteína } \\
\text { ácida }\left(\mathrm{g} \mathrm{L}^{-1}\right)\end{array}$ \\
\hline 1 & 0,07 & 8,0 & 0,82 \\
2 & 0,47 & 16,0 & 1,01 \\
3 & 0,99 & 12,0 & 1,15 \\
4 & 1,32 & 13,0 & 1,39 \\
5 & 0,65 & 11,0 & 0,71 \\
6 & 0,01 & 13,0 & 0,61 \\
7 & 0,62 & 11,0 & 0,56 \\
8 & 0,77 & 12,0 & 0,74 \\
9 & 1,13 & 11,0 & 0,54 \\
10 & 0,70 & 12,0 & 0,54 \\
11 & 0,75 & 12,0 & 0,73 \\
Valor & 1,32 & 16,0 & 1,39 \\
máximo & & & 0,54 \\
Valor & 0,01 & 8,0 & \\
mínimo & & & \\
\hline
\end{tabular}

\section{DISCUSSÃO}

Todos os cães doentes, incluídos no Grupo II, apresentaram leucopenia devido à depleção dos órgãos linfóides e do comprometimento da granulocitopoiese, indicando que o processo infeccioso causado pelo CPV encontrava-se em seu pico (HAGIWARA et al., 1984). Por se tratar de um processo inflamatório agudo, embora causado por um vírus, havia a expectativa do aumento dos níveis séricos das PFA, como foi citado por GANROT, 1973; SOLTER etal., 1991, BAUMANN \& GAULDIE, 1994; CORAZZA et al., 1997. Todas as PFA avaliadas encontraram-se em

Tabela 2 - Valores individuais, máximos e mínimos da haptoglobina, ceruloplasmina e $\alpha$-glicoproteína ácida séricas em cães com gastrenterite hemorrágica (GEH) e leucopenia. São Paulo, 2000.

\begin{tabular}{lccc}
\hline Animal & $\begin{array}{c}\text { Haptoglobina } \\
\left(\mathrm{mg} \mathrm{dl}^{-1}\right)\end{array}$ & $\begin{array}{c}\text { Ceruloplasmina } \\
\left(\mathrm{U} \mathrm{l}^{-1}\right)\end{array}$ & $\begin{array}{c}\alpha \text {-Glicoproteína } \\
\text { ácida }\left(\mathrm{mg} \mathrm{dl}^{-1}\right)\end{array}$ \\
\hline 1 & 2,51 & 19,4 & 3,33 \\
2 & 2,50 & 17,5 & 2,55 \\
3 & 2,46 & 23,1 & 2,81 \\
4 & 2,57 & 20,6 & 2,34 \\
5 & 2,34 & 18,1 & 2,53 \\
6 & 2,58 & 16,3 & 1,71 \\
7 & 2,57 & 19,4 & 2,35 \\
8 & 2,68 & 11,8 & - \\
9 & 2,39 & 18,1 & 1,83 \\
10 & 2,10 & 13,0 & 1,45 \\
11 & 2,70 & 14,6 & 3,33 \\
Valor & 2,70 & 23,1 & \\
máximo & & & 1,05 \\
Valor & 2,10 & 11,8 & \\
mínimo & & & \\
\hline
\end{tabular}

Ciência Rural, v. 33, n. 3, mai-jun, 2003. 


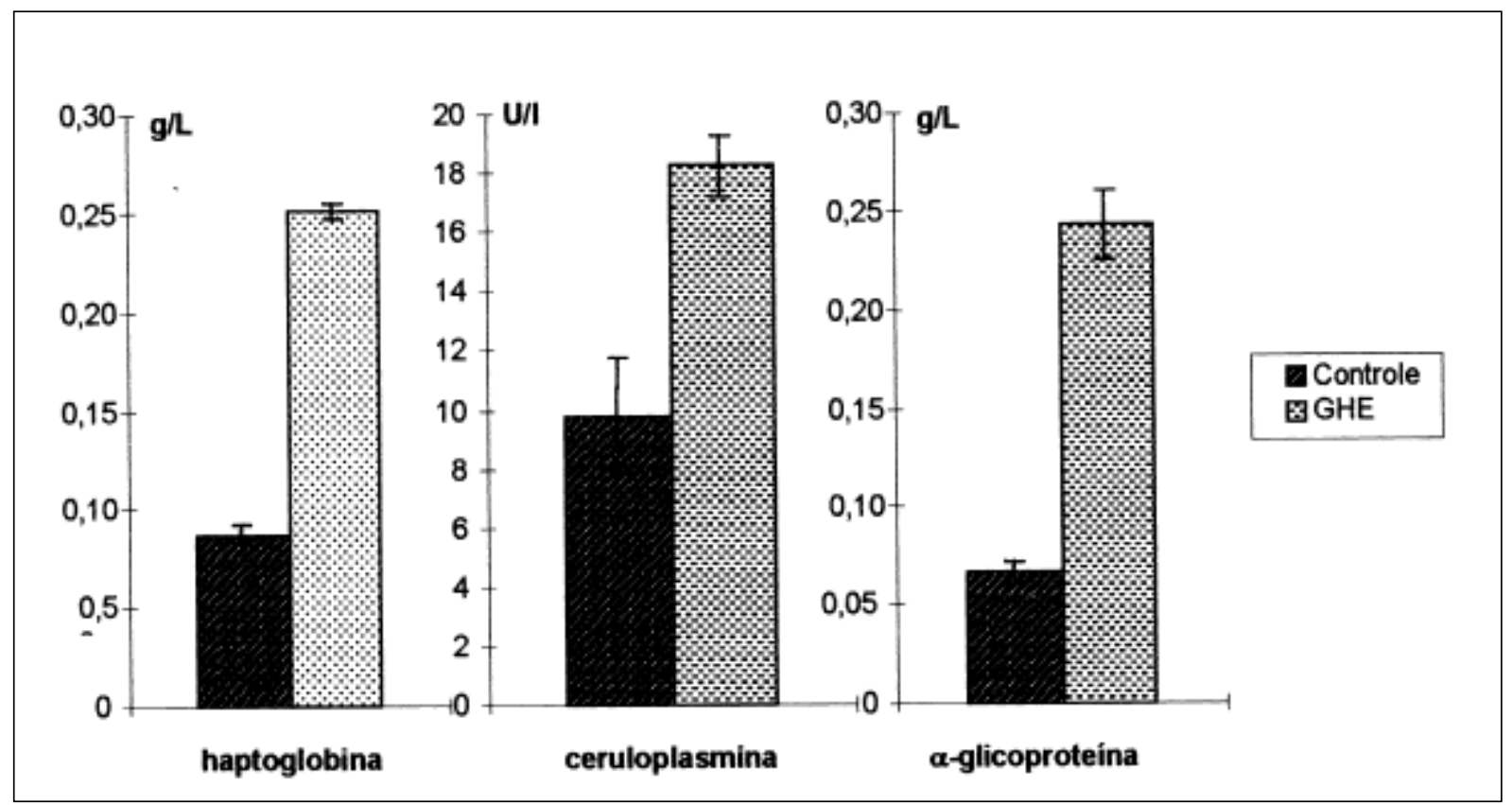

Figura 1 - Representação gráfica das médias e dos erros padrões da média obtido nas mensurações das Proteínas de Fase Aguda (haptoglobina, ceruloplasmina e $\alpha$-glicoproteína ácida) dos animais do grupo controle e dos cães com gastrenterite hemorrágica (GHE) e leucopenia. São Paulo, 2000.

concentrações maiores na circulação sanguínea quando comparadas com as dos animais saudáveis de faixa etária similar.

Dentre as PFA analisadas, a ceruloplasmina foi, aparentemente, a de menor produção diante do processo inflamatório agudo, apresentando aumento discreto quando comparado ao das outras PFA, fato que também havia sido observado por GANROT (1973). De acordo com CONNER et al. (1988), a ceruloplasmina é liberada na circulação sangüínea imediatamente após a instalação do processo inflamatório, sendo encontrada em níveis 1,4 vezes maior do que no momento anterior ao dano tecidual e permanecendo elevada por até nove dias (GANROT, 1973). Assim, a ceruloplasmina poderia ser determinada como um indicador precoce do processo inflamatório.

Tanto a haptoglobina quanto à $\alpha$ glicoproteína ácida encontravam-se extremamente aumentadas na circulação sangüínea dos animais do Grupo II (doentes) quando comparadas aos do Grupo I (saudáveis). A $\alpha$-glicoproteína ácida foi a que se alterou de forma mais evidente nos processos inflamatórios nos cães com GEH do presente estudo, estando de acordo com os dados encontrados por GANROT (1973). O pico da elevação sérica dessa proteína ocorre ao redor do $3^{\circ}$ ao $4^{\circ}$ dia do processo inflamatório (ARONSEN et al., 1972) e mantem-se elevado por até 12 dias (GANROT, 1973), o que permite a indicação da $\alpha$-glicoproteína ácida como sendo o parâmetro de eleição para a avaliação do processo inflamatório agudo. Também em relação à haptoglobina, o aumento dos níveis séricos foi evidente no momento em que o animal se encontrava leucopênico. De acordo com HARVEY \& WEST (1987), o aumento da haptoglobina sérica é observado a partir do primeiro dia do processo inflamatório, atingindo o ápice ao redor do 3을 dia e retornando aos valores basais no 9․ Uma característica dessa PFA é a de que seu aumento ocorre de forma mais discreta nos processos inflamatórios virais e de forma mais acentuada nas infecções bacterianas (JAIN, 1989). O aumento dos níveis séricos apresentados pelos animais do grupo II pode ser indicativo, portanto, de uma infecção bacteriana secundária. HAGIWARA et al. (1996) demonstraram que, na GEH causada pelo CPV, ocorre, nos casos mais graves, a invasão da corrente sangüínea pela flora bacteriana intestinal, causando endotoxemia ou septicemia de origem bacteriana. Nessas condições, a leucopenia induzida pela infecção viral não permite caracterizar hematologicamente o processo inflamatório agudo de origem bacteriana.

Desta forma, a avaliação da haptoglobina poderá ser útil na indicação da infecção bacteriana secundária nos casos de GEH causada pelo CPV e a determinação simultânea dos níveis séricos de $\alpha$ glicoproteína ácida e de haptoglobina poderá auxiliar 
na avaliação mais acurada quanto à gravidade do processo inflamatório decorrente da infecção pelo CPV.

\section{AGRADECIMENTOS}

Agradecemos à Camila Infantosi Vannucchi e Regina Mieko S. Mirandola pelas contribuições técnicas laboratoriais.

\section{REFERÊNCIAS BIBLIOGRÁFICAS}

ARONSEN, K.F. et al. Sequential changes of plasma proteins after surgical trauma. Scand J Clin Lab Invest, v.29, Suppl.124, p.127-136, 1972

BAGGINI, S.P. Parvovirosis canina. Veterinaria Argentina v.9. n.81, p.43-46, 1991.

BAUMANN, H.; GAULDIE, J. The acute phase response. Immunology Today, v.15, n.2, p.74-80, 1994.

CONNER, J.G. et al. Acute phase response in the dog following surgical trauma. Research in Veterinary Science, v. 45, n.1, p.107-110, 1988 .

CORAZZA, M. et al. Dati preliminari sulla determinazione dell'aptoglobinemia in cani sani ed affetti da patologie in fase acuta e cronica. Annali della Facolta di Medicina Veterinaria de Pisa, v.L, p.241-249, 1997.

DE LA HUERGA, J. et al. Studies of serum mucoprotein (seromucoid). I. A turbidimetric method. Journal Lab and Clin Med, v.47, n.3, p.403-408, 1956

DELLO, C.P. et al. Influence of inflammation on serum concentration, molecular heterogeneity and drug binding properties of canine alpha-1-acid glycoprotein. Journal of Veterinary Pharmacology and Therapeutics, v.11, n.1, p.71-76, 1988 .

ELSON, E.C. Quantitative determination of serum haptoglobin. A simple and rapid method. American Journal of Clinical Pathology, v.62, n.5, p.655-663, 1974.
GANROT, K. Plasma protein response in experimental inflammation in the dog. Research Experimental Medicine, v.161, n.4, p.251-261, 1973.

GRUYS, E.; OBWOLO, M.J.; TOUSSAINT, M.J.M. Diagnostic significance of the major acute phase proteins in veterinary clinical chemistry: a review. Veterinary Bulletin, v.64, n.11, p.1009-1018, 1994.

HAGIWARA, M.K.; MAMIZUKA, E.M.; PAVAN, M.F.B. Role of intestinal flora in acute hemorrhagic gastroenteritis (parvovirus infection) of dogs. Braz J Vet Res An Sci, v.33, n.2, p.107-109, 1996

HAGIWARA, M. K.; LARSSON, M.H.M.A.; PEREIRA, D. Estudo das variações hematológicas na parvovirose canina. Revista Brasileira Medicina Veterinária, v.6, n.2, p.5255, 1984.

HARVEY, J.W.; WEST, C.L. Prednisone-induced increases in serum alpha-2-globulin and haptoglobin concentration in dogs. Veterinary Pathology, v.24, n.1, p.90-92, 1987.

JAIN, N.C. Acute phase proteins. In: KIRK, R.W. Current veterinary therapy $X$ : small animal practice. Philadelphia: Saunders, 1989. p.468-471.

JAIN, N.C. The plasma proteins, dysproteinemias, and immune deficiencydisorders. In: JAIN, N.C. Essentials of veterinary hematology. Philadelphia : Saunders, 1993. p.349-380.

SCHOSINSKY, K.H.; LEHMANN, H.P.; BEELER, M.F. Measurement of ceruloplasmin from its oxidase activity in serum by use of o-dianisidine dihydrochloride. Clinical Chemistry, v.20, n.12, p.1556-1563, 1974.

SHERDING, R.G. Virus intestinais. In: . Manual Saunder - Clínica de pequenos animais. São Paulo : Roca 1988. p.124-127.

SOLTER, P.F. et al. Haptoglobin and ceruloplasmin as determinants of inflammation in dogs. American Journal of Veterinary Research, v.52, n.10, p.1738-1742, 1991. 